\title{
Analysis of the Effect of a Marine Energy Farm to Protect a Biosphere Reserve
}

\author{
Eugen Rusu, a \\ ${ }^{1}$ Department of Mechanical Engineering, 'Dunarea de Jos' University of Galati, Romania
}

\begin{abstract}
Sacalin Peninsula in the Black Sea is a new land located south of the Saint George branch of the Danube. Since 1938 this area became a biosphere reserve since many rare species of animals and plants are to be found there. The generation of this new peninsula is due to the sedimentary process induced by the Danube River outflow and it was started more than 150 years ago. In the winter of 2013 this environment was seriously affected by some very strong storms putting in real danger this ecosystem. From this perspective, the objective of the present work is to evaluate the protection that might be offered to this area by a marine energy farm that would be deployed in front of the peninsula. In order to assess the coastal protection offered by the proposed solution, simulations with the SWAN (Simulating Waves Nearshore) wave model have been performed for the most relevant storm patterns. The results show that a marine energy farm can provide a real sheltering effect to the ecological reserve. Such approach seems to be also economically viable since this coastal environment represents a real hot spot in the Black Sea from the point of view of marine energy resources.
\end{abstract}

\section{Introduction}

Sacalin is a newly created peninsula in the Black Sea, close to the southern branch (Saint George) of the Danube River. The process of the land generation started more than 150 years ago (at about 1850) due to the sediments transported by the river outflow. It was first developed as an island system, composed by two nearshore islands, Great Sacalin (Sacalinu Mare) and Small Sacalin (Sacalinu Mic). However, in the last decades, due to the sedimentary process the islands were linked together with the mainland generating in this way a peninsula.

Nowadays, the Sacalin Peninsula has a length of about $18.3 \mathrm{~km}$. At this point, it has to be highlighted that a measurement performed in 1977 gave a length of only about $14 \mathrm{~km}$, fact that demonstrates that this is a very dynamically changing coastal environment. As regards the width of the island this is variable. In the north, decreases from about 830 meters to about 350 meters. However it is really hard to estimate the width in the northern part since the island joined the mainland in a peninsula. For the rest of the peninsula, the width varies between $100-150$ meters. Finally we can mention also that now the surface of the peninsula is over 21000 hectares. The position of the Sacalin Peninsula in relationship with the Romanian nearshore is illustrated in Figure 1. In the right upper side of this figure, the bathymetric map of the target area is illustrated suggesting also the longshore currents induced by the Danube River outflow.

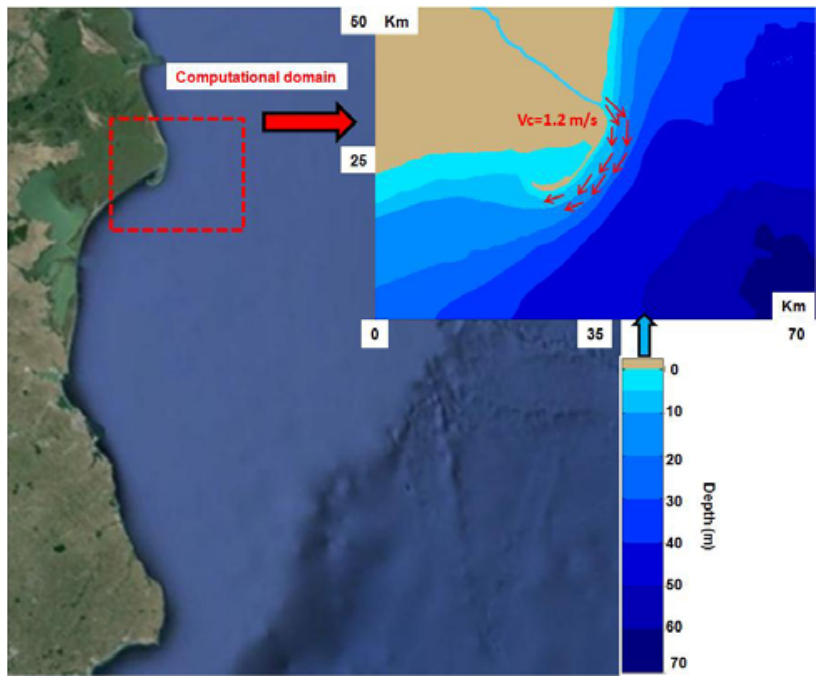

Figure 1. The Romanian nearshore and the target area of the present study (the Sacalin Peninsula). In the upper side the bathymetric map of the target area is illustrated representing also the longshore currents induced by the Danube River outflow

During the time, various rare species of animals have been settled in this environment. Thus, besides about 230 species of birds, which it was discovered that are nesting for the summer in that area, rare species of reptiles and mammals are also to be found there together with some rare plants, such as cabbage and marsh canary. That is why in 1938 this area was declared an ecological reserve and the access of the tourists is nowadays not allowed.

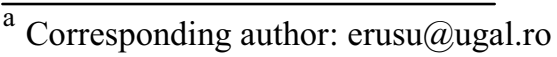


Despite the fact that there is an obvious natural tendency to enlarge this costal environment due to the sediment transport patterns, in the winter of 2013 a sequence of very strong storms practically broke the peninsula putting in real danger all the rare species of animals and plants living there. From this perspective, in order to provide a realistic explanation related to the causes that generated these damages to the Sacalin biosphere reserve, Rusu and Butunoiu [1] performed some high resolution simulations with numerical wave models considering the most relevant wave propagation patterns. They used for this the spectral phase averaged model SWAN (Simulating Waves Nearshore) [2]. Their results put in evidence the fact that there is a dominant process of driving the sediments brought by the Danube towards the south.

This was called the 'constructive process' and corresponds to the most relevant pattern of the wave propagation, that is when the direction of the incoming waves is from north, northeast. Nevertheless, when the direction of the incoming waves is from the south, the results show that the wave forces are considerably higher and in the case of the strong storms, the waves may penetrate the peninsula as it was happened in the winter of 2013. Since such phenomena can happen again sometime in the future, as a continuation of [1], the present work explores the possibility of deploying a marine energy farm that may have as an effect also the coastal protection of the Sacalin ecological reserve.

\section{Wave modelling and relevant environmental patterns in the Black Sea}

The wave and wind climate in the Black Sea became in the last decades an issue of increasing importance. This is due to the continuous enhancement of the human nearshore and offshore activities, including also a significant increase of the maritime traffic.

In order to provide reliable information concerning the wave conditions in the Black Sea, a multi-level wave prediction system, SWAN based was implemented [3, 4]. SWAN is a spectral phase averaged wave model, which integrates the spectral action balance equation in time, geographical and spectral spaces. The system comprises a large computational domain that covers the entire Black Sea basin and the Sea of Azov, which is subsequently focused towards various coastal areas. The advantage is that one single model covers the full scale of the modelling process, although the physical processes considered in each computational domain might be rather different from one computational level to another. Moreover, in order to improve the reliability of the wave predictions, some data assimilation technique have been also implemented, considering either satellite data [3], or in situ measurements [5].

A very important area in the Black Sea, from the point of view of the maritime traffic, is that located in front of the Danube Delta. This is also the principal southern gate in the seventh Pan European transportation corridor. On the other hand, the interactions that occur between the relatively strong waves and the currents produced by the
Danube River outflow induce a wide variety of processes and phenomena, sometimes rather unusual. For this reason, several studies were focused on this coastal environment as for example $[6,7,8]$.

For the present work, the characteristics of the computational domain, the input fields considered and the physical processes activated are briefly presented in Table 1

Table 1. Characteristics of the computational domain defined and the main physical processes activated.

\begin{tabular}{|c|c|c|c|}
\hline \multicolumn{2}{|c|}{$\begin{array}{c}\text { Computational grid } \\
\text { characteristics }\end{array}$} & \multicolumn{2}{c|}{ Input or process } \\
\hline Coordinates & Cartesians & Waves & $\mathrm{X}$ \\
\hline$\Delta \mathrm{x}(\mathrm{m})$ & 200 & Wind & $\mathrm{X}$ \\
\hline$\Delta \mathrm{y}(\mathrm{m})$ & 200 & Current & $\mathrm{X}$ \\
\hline$\Delta \theta\left(^{\circ}\right)$ & 5 & Gen & Westh. \\
\hline $\begin{array}{c}\text { No points in X- } \\
\text { direction }\end{array}$ & 351 & Interactions & $\begin{array}{c}\text { Quad. } \\
\text { Triads }\end{array}$ \\
\hline $\begin{array}{c}\text { No points in Y- } \\
\text { direction }\end{array}$ & 251 & Whitecapp. & $\mathrm{X}$ \\
\hline No of frequencies & 35 & Refraction & $\mathrm{X}$ \\
\hline No of directions & 36 & Diffraction & $\mathrm{X}$ \\
\hline Mode & Stationary & $\begin{array}{c}\text { Nearshore } \\
\text { processes }\end{array}$ & $\begin{array}{c}\text { Friction } \\
\text { Breaking } \\
\text { Set up }\end{array}$ \\
\hline
\end{tabular}

As regards the possibility of deploying a marine energy farm in the coastal environment of the Black Sea, it has to be highlighted that although the wave conditions are less energetic than in the ocean, the idea of the hybrid farms seems however to be viable. Moreover, various studies $[9,10]$ showed that the wind energy potential in the Black Sea is in line with that from other locations where offshore wind farms already operate successfully. On the other hand, other previous studies [11, 12] indicated that besides renewable energy, such hybrid farms may provide also an effective coastal protection.

\section{Analysis of four scenarios}

Previous analyses performed in the Black Sea $[3,13]$ put in evidence that the western part of the sea is its most energetic part. Thus, every winter at least one or two storms occur characterised by significant wave heights greater than 7 meters. Such events can be called trivial strong storms.

Nevertheless, extreme storms may also occur in a time widow usually smaller than a decade. In such cases significant wave heights even greater than 10 meters can be noticed. From a statistical perspective there can be defined two geographic regions where the maximum waves are encountered. One is in the south-western part of the sea, offshore the border between the Bulgarian and the Turkish coastal environments and the other in the north-western part of the sea, offshore the mouth of the Danube. 
Based on these data, four different environmental scenarios from the point of view of the directions of the wave propagation have been defined and they are presented in Table 2. Corresponding to each scenario and energy case, model simulations have been carried out for the present situation when no farm or other coastal protection are present and also considering various configurations of marine energy farms in front of the Sacalin Peninsula and also considering various transmission ratios in terms of significant wave height (Hs). Figures 2, 3, 4 and 5 present the results for the four scenarios and energy cases considering a transmission ratio of $60 \%$. Figure 6 , presents in more detail the location in the target area of the marine farm that was found more appropriate for the coastal protection and the positions of 8 pairs of reference points corresponding to water depths of about 5 (nearshore points - NP) and 8 meters (offshore points - OP), respectively.

Table 2. Description of the four scenarios considered.

\begin{tabular}{|c|c|c|c|c|c|}
\hline Scenario & $\begin{array}{c}\text { Direction on } \\
\text { boundary in } \\
\text { Nautical } \\
\text { convention }\left({ }^{\circ}\right)\end{array}$ & \multicolumn{2}{|c|}{$\begin{array}{c}\text { High waves } \\
\text { Case A }\end{array}$} & \multicolumn{2}{|c|}{$\begin{array}{c}\text { Case B } \\
\text { Extreme } \\
\text { waves }\end{array}$} \\
\cline { 1 - 2 } S1 & 30 & & & & \\
\cline { 1 - 2 } S2 & 90 & Hs & Tp & $\begin{array}{c}\mathrm{Hs} \\
10 \mathrm{~s}\end{array}$ & $\begin{array}{c}\mathrm{Tp} \\
12 \mathrm{~m}\end{array}$ \\
\cline { 1 - 2 } S3 & 150 & & & & \\
\cline { 1 - 2 } S4 & 200 & & & & \\
\hline
\end{tabular}

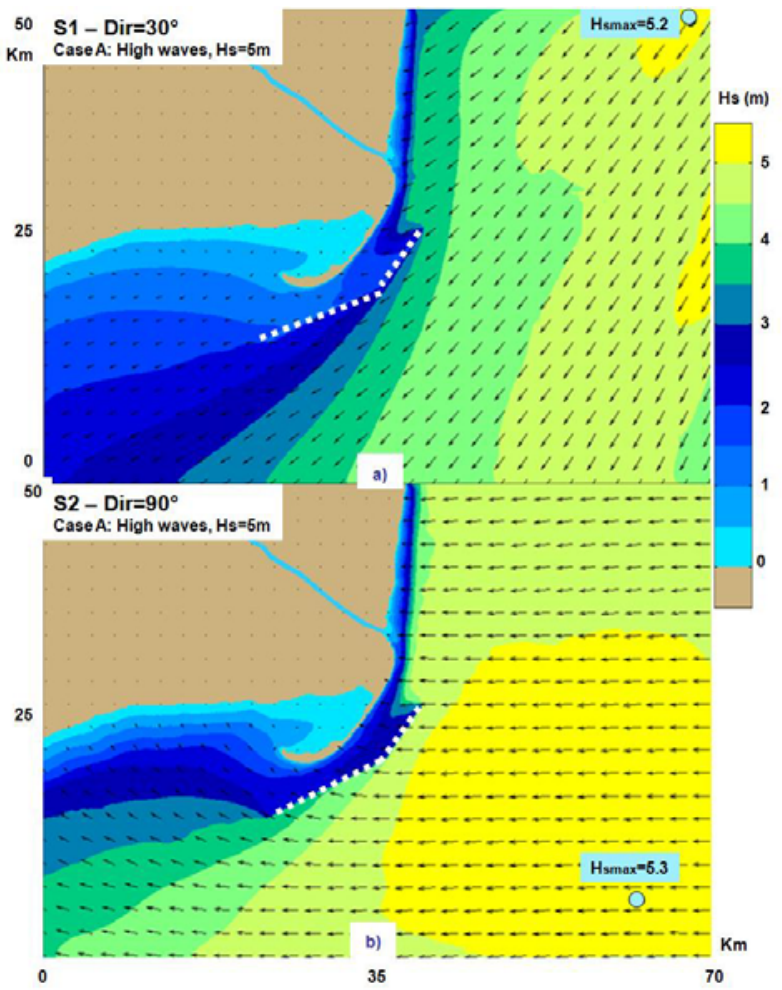

Figure 2. Case A - high waves, significant wave heights fields and wave vectors, a) S1 - wave direction on the boundary $30^{\circ}$ in Nautical convention; b) S2 - wave direction on the boundary $30^{\circ}$ in Nautical convention.

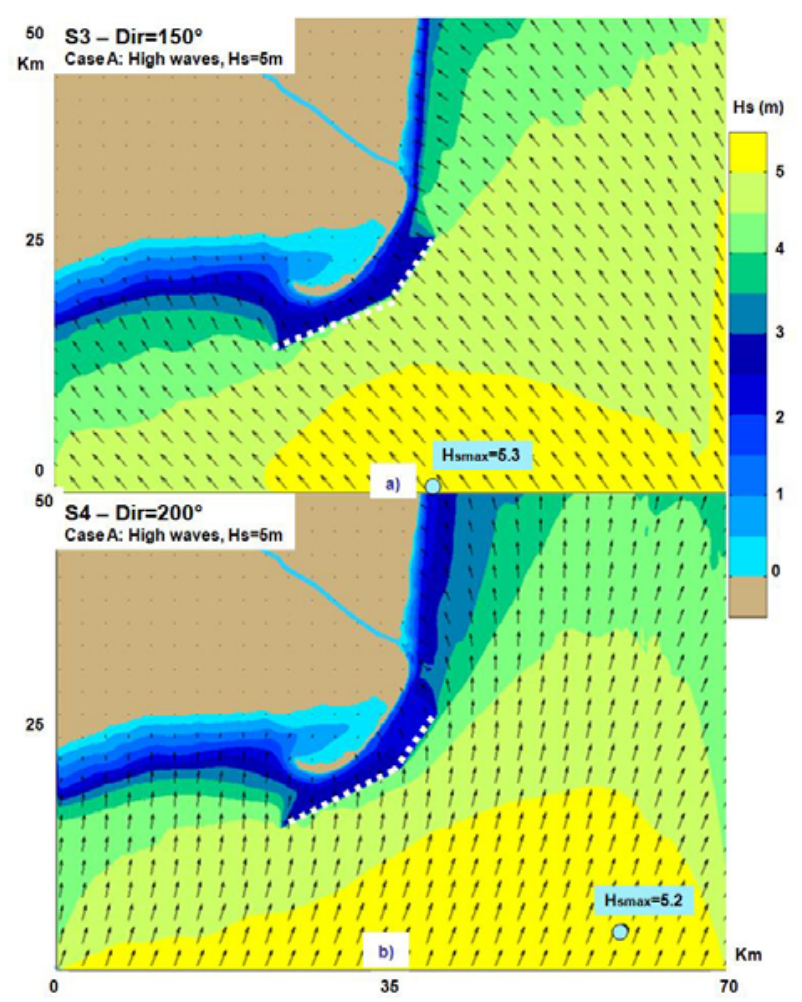

Figure 3. Case A - high waves, significant wave heights fields and wave vectors, a) $\mathrm{S} 3$ - wave direction on the boundary $150^{\circ}$ in Nautical convention; b) S4 - wave direction on the boundary $200^{\circ}$ in Nautical convention.

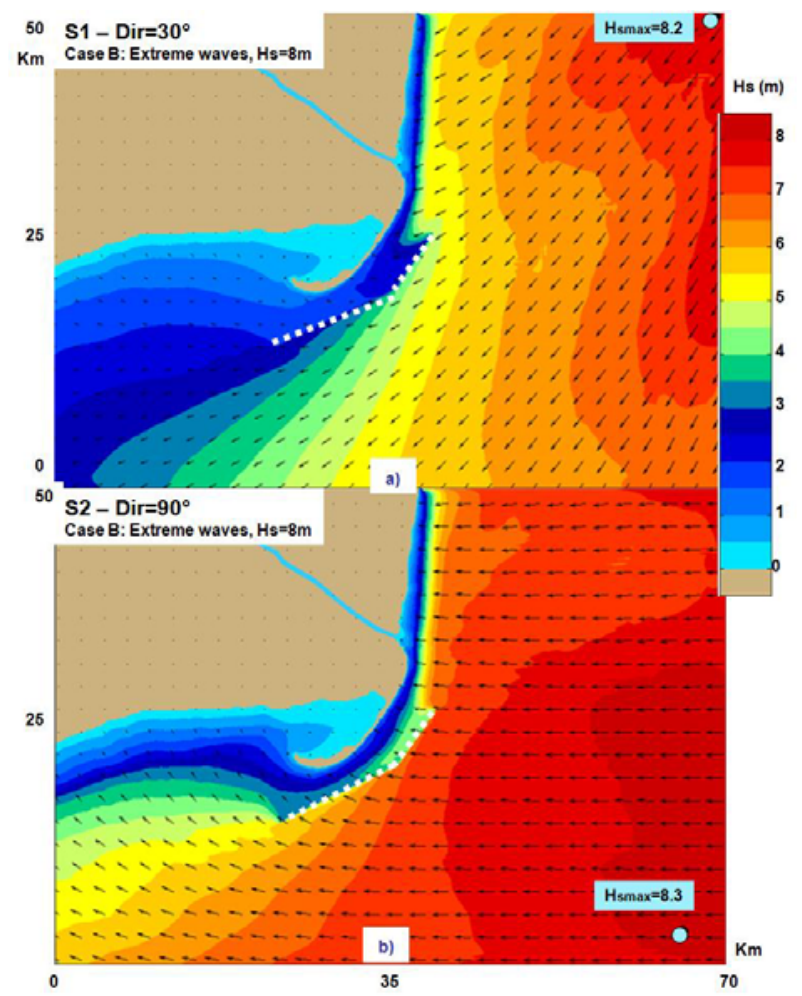

Figure 4. Case B - extreme waves, significant wave heights fields and wave vectors, a) S1 - wave direction on the boundary $30^{\circ}$ in Nautical convention; b) S2 - wave direction on the boundary $30^{\circ}$ in Nautical convention. 


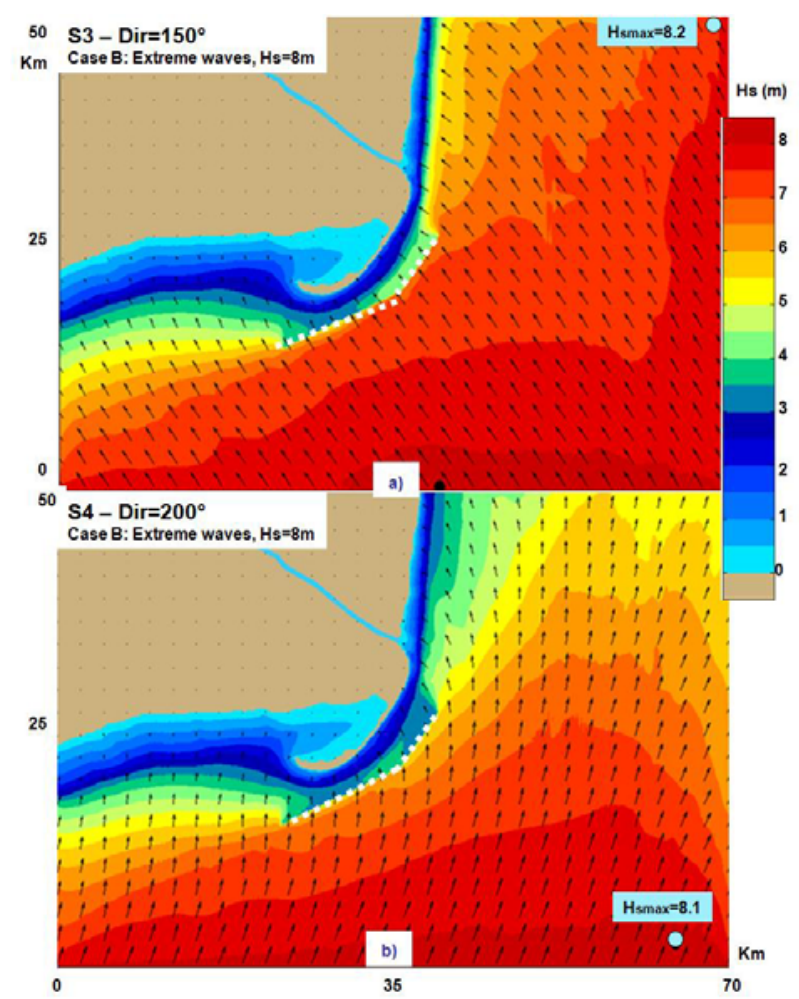

Figure 5. Case B - extreme waves, significant wave heights fields and wave vectors, a) S3 - wave direction on the boundary $150^{\circ}$ in Nautical convention; b) S4 - wave direction on the boundary $200^{\circ}$ in Nautical convention.

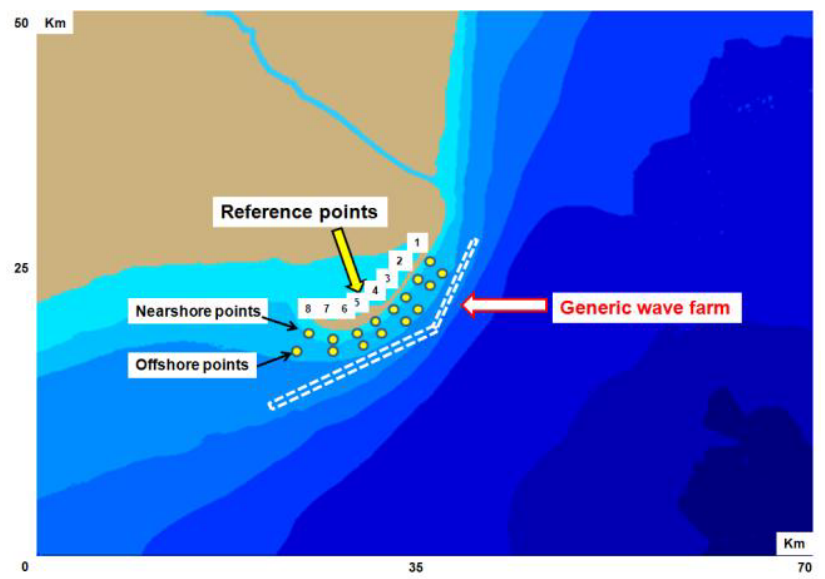

Figure 6. Location in the target area of the marine farm and of the 8 pairs of reference points corresponding to water depths of about 5 and 8 meters, respectively.

\section{Discussions}

A first issue to be discussed at this point is related to the efficiency of such a marine energy farm in the nearshore of the Black Sea. As it was explained before, although less energetic than the coasts of the oceans, the target area is one of the most energetic in the Black Sea form the point of view of the waves. As regards the wind power this is in line and sometimes even superior than in places where wind farms already successfully operate. From this perspective, the idea of a hybrid marine energy farm appears to realistic enough.
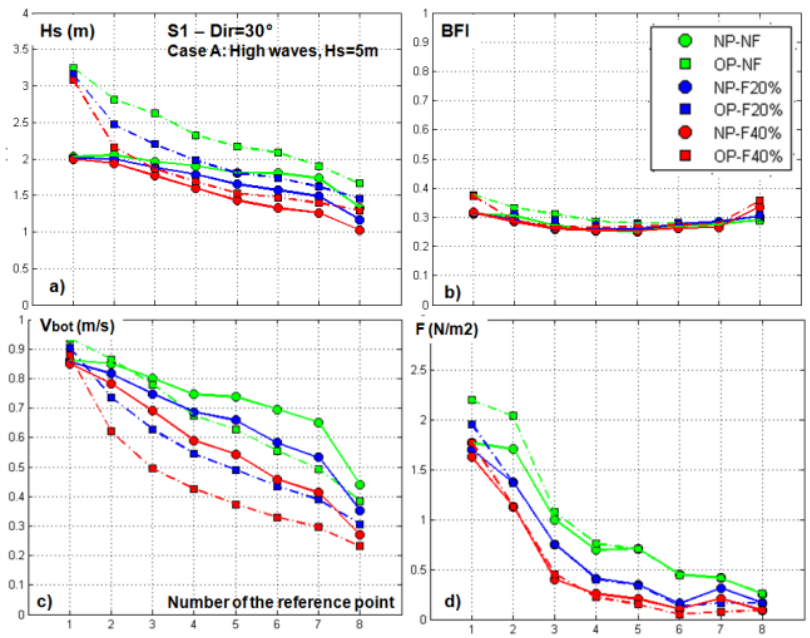

Figure 7. Case A - high waves, S1 - wave direction on the boundary $30^{\circ}$; variations along the 8 reference points: a) Hs; b) BFI; c) Vbot; d) F.
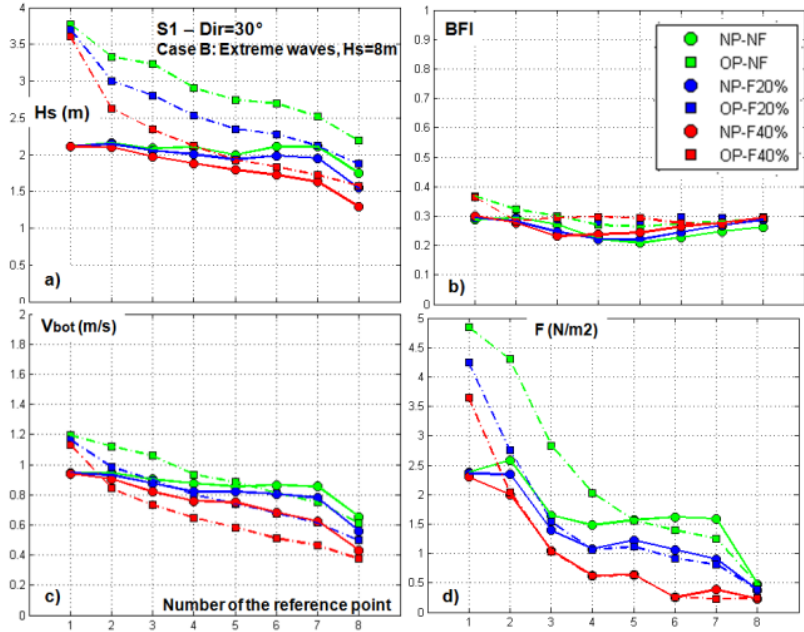

Figure 8. Case B - extreme waves, S1 - wave direction on the boundary $30^{\circ}$; variations along the 8 reference points: a) Hs; b) BFI; c) Vbot; d) F.
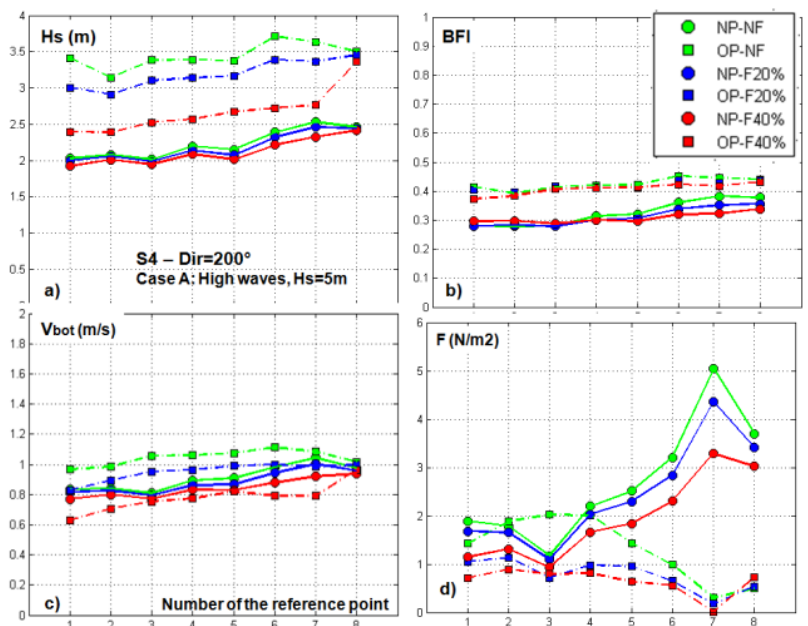

Figure 9. Case A - high waves, S4 - wave direction on the boundary $200^{\circ}$; variations along the 8 reference points: a) Hs; b) BFI; c) Vbot; d) F. 

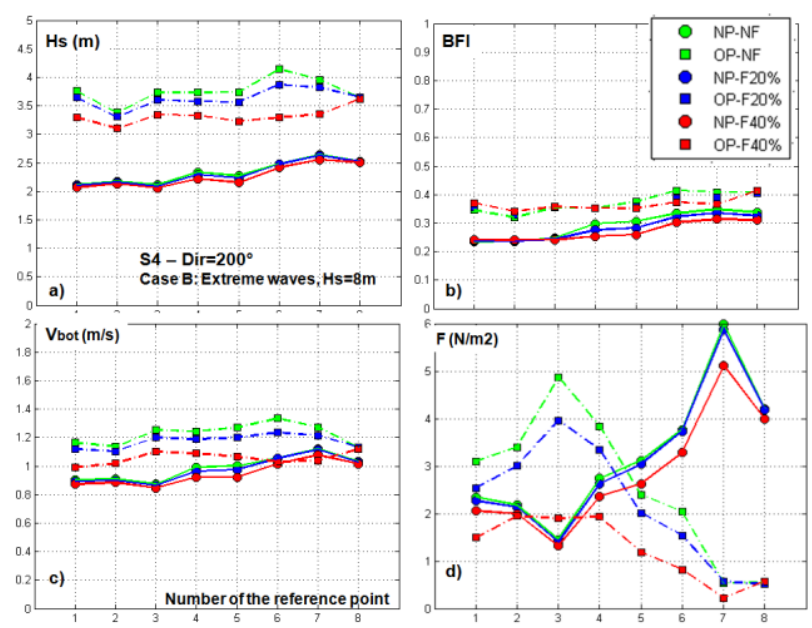

Figure 10. Case B - extreme waves, S4 - wave direction on the boundary $200^{\circ}$; variations along the 8 reference points: a) Hs; b) BFI; c) Vbot; d) F.

As regards the coastal protection, various studies (see for example [14]) showed that the coastal works are very expensive. Thus, a marine farm might represent an option for such cases. Figures 7, 8, 9 and 10 present the values in the reference points of the parameters Hs (significant wave height), BFI (Benjamin Feir Index that indicates if there is a higher probability of the apparition of the extreme waves in relationship with the standard Rayleigh distribution), Vbot (orbital velocity at the bottom) and $\mathrm{F}$ (wave forces) corresponding to three relevant situations: NF - no farm, F20\% - farm with 20\% absorption (including reflections) and F40\% - farm with 40\% absorption. Thus, the results presented in Figures 7, 8, 9 and 10 demonstrate that the presence of the marine farm may provide a protection to the Sacalin Peninsula.

\section{Conclusions}

The present work explores the possibility to implement a marine energy farm in order to protect an important and unique biosphere reserve in the Black Sea. Besides the fact that a hybrid marine energy farm might be economically viable, the results presented show that such a project might play an important role in protecting the coastal area targeted.

Thus, when the waves come from the south, the wave forces become considerably higher, almost double for the high waves than in case of the waves coming from the north, north-east. Such situations of high and extreme waves coming from the south are not very likely to be encountered, but they are possible and in fact this was the case that almost destroyed the peninsula in the winter of 2013.

\section{Acknowledgements}

This work was supported by a grant of the Romanian Ministry of National Education, CNCS - UEFISCDI, project number PN-II-here ID-PCE-2012-4-0089 (project DAMWAVE).

\section{References}

1. L. Rusu, D. Butunoiu, Journal of Marine Science and Technology - Taiwan 23, 669-677(2015)

2. N. Booij, R.C. Ris, L. H. Holthuijsen, J. Geophys, Res. 104, 7649-7666 (1999)

3. L. Rusu, Energies 2015 8, 10370-10388 (2015)

4. D. Butunoiu, E. Rusu. Journal of Environmental Protection and Ecology 13, 1332-1349 (2012)

5. D. Butunoiu, E. Rusu. Proceedings of the Second International Conference on Traffic and Transport Engineering ICTTE, Belgrade, 180-187 (2014)

6. A. Ivan, C. Gasparotti, E. Rusu, Journal of Environmental Protection and Ecology 13, 16731682 (2012).

7. A. Ivan, L. Rusu, Environmental Engineering and Management Journal 14, 751-761 (2015)

8. E. Rusu, S. Macuta, Environmental Engineering and Management Journal 8, 147-151 (2009)

9. F. Onea, E. Rusu, International Journal of Green Energy 11, 465-487 (2014)

10. F. Onea, E. Rusu, Meteorological Applications 21, 316-329 (2014)

11. A. Zanopol, F. Onea, E. Rusu, Energy 72, 652-670 (2014)

12. S. Diaconu, E. Rusu, The Scientific World Journal, Article Number: 498013, (2013)

13. L. Rusu, D. Butunoiu, E. Rusu, Journal of Environmental Protection and Ecology 15, 445-454 (2014)

14. I. Omer, R. Mateescu, L. Rusu, D. Niculescu, E. Vlasceanu, Journal of Environmental Protection and Ecology16, 424-433 (2015) 